\title{
Improving the Performance of Failing Students by Overcoming Their Self-Serving Attributional Biases
}

\author{
Jeffrey G. Noel, Donelson R. Forsyth, and \\ Karl N. Kelley \\ Virginia Commonwealth University
}

\begin{abstract}
The causal impact of attributions on academic performance was examined by changing low-scoring students' attributions regarding their poor performances. Initially, when students who were failing a college course identified the cause of the performance, they emphasized external, uncontrollable causes. Because these self-serving attributions could have perpetuated poor performance on subsequent examinations, students in the experimental condition were exposed to information that suggested that grades in college are caused by internal, controllable factors such as effort and motivation. As predicted, on subsequent tests and on the final examination, these students earned higher grades than control students who received no attributional information. These findings lend support to an attributional model of academic achievement and also suggest that educational interventions that shift attributions away from a selfserving pattern to a performance-facilitating pattern may improve academic outcomes.
\end{abstract}

When people describe the causes of their successes and failures, they generally blame their failures on inhibiting external factors, whereas they attribute their successes to the causal impact of internal factors. This pattern, variously termed beneffectance (Greenwald, 1980), egocentrism (Forsyth \& Schlenker, 1977), and egotism (Snyder, Stephan, \& Rosenfield, 1978), has been documented in a number of studies of students' attributions about their

Requests for reprints should be sent to Jeffrey G. Noel or Donelson R. Forsyth, Department of Psychology, Virginia Commonwealth University, 810 West Franklin Street, Richmond, VA 23284. 
educational outcomes. For example, when Bernstein, Stephan, and Davis (1979) asked college students to describe the cause of their performance on their exams, the high-scoring students, relative to students who were doing poorly, felt that effort and ability were more important causes, but the nature of the test and luck were less important. Using a similar method, Kovenklioglu and Greenhaus (1978) found that sucessful students emphasized the causal importance of ability and effort, whereas failing students cited bad luck and the difficulty of the test (see Forsyth, 1986; Zuckerman, 1979).

These attributional patterns may be self-serving: By emphasizing external factors, failing students can avoid any loss of self-esteem, and successful students can increase their confidence and sense of personal worth by attributing their performance to internal factors (Arkin \& Maruyama, 1979; Covington \& Beery, 1976; Covington \& Omelich, 1979, 1981; Forsyth, 1980). However, although self-serving in the short run, these attributional patterns may have a detrimental effect on students' overall academic performance. If failing students attribute their performance to external, environmental factors that are beyond personal control, they may develop more negative expectations (Forsyth \& McMillan, 1981), experience losses in motivation (Arkin, Kolditz, \& Kolditz, 1983), and fail to take steps to improve their grades (e.g., seeking help; Ames \& Lau, 1982). In contrast, if successful students feel that their outcome is due to ability, which is a stable, internal cause, then they may become so complacent that they no longer prepare adequately (Bernstein et al., 1979). Thus, so-called self-serving attributions may, in the long run, actually be self-damaging.

The current research is based on the assumption that low-scoring students will show improved performance if their attributions are shifted away from a self-serving pattern to a performance-facilitating pattern. Attributing their outcomes to internal, controllable factors such as effort, motivation, and self-control was selected as the more efficacious pattern of making attributions. The emphasis on internal, controllable causes was based on both theory and previous research. In theory, if individuals who fail attribute that outcome to internal factors that they can control, they should feel personally responsible for their performance. Empirically, internal, controllable information has had positive effects in both clinical and educational settings. Forsyth and Forsyth (1982), for example, found that stressing internal, controllable factors as the cause of social anxiety resulted in significant improvement in some individuals. Within educational settings, when Dweck (1975) trained children who displayed maladaptive reactions to failure to attribute both success and failure to effort, they no longer showed losses in motivation and persistence if they failed. Miller, Brickman, and Bolen (1975) and Schunk (1983) compared the effectiveness of ability attributions (internal, noncontrollable), effort attributions (internal, controllable), and no attributions. They found that effort attributions had the most positive impact on 
students. Lastly, although Wilson and Linville (1982) focused on the stability dimension - they exposed students to information that suggested grades generally change to become more positive during college-by emphasizing change, they may have convinced their participants that grades are caused by controllable (and possibly internal) factors.

Thus, we hypothesized that failing students who were trained to attribute their performance to internal, controllable factors would show improved performance relative to untrained failing students. This hypothesis was tested using techniques adapted from Wilson and Linville (1982, 1985; see Block \& Lanning, 1984). Students who obtained very low grades on the first two examinations in a college course were exposed to information that suggested examination performance is primarily caused by internal, controllable factors such as effort, internal motivation, self-control, and internal control. This information was conveyed to participants through videotaped interviews of seniors who explained that they overcame their initial failures when they realized that examination performance can be controlled through personal effort. In addition, participants received written information that summarized these same claims. At the end of the semester, participants' test scores were compared to grades earned by control participants who were not exposed to the attributional information. We predicted:

1. Failing students would spontaneously attribute their performance to external, uncontrollable factors.

2. Failing students who were exposed to the information emphasizing the causal significance of internal, controllable factors would cite more internal, controllable causes when explaining their subsequent performances.

3. Students who shifted their attributions would make better grades on subsequent tests than students who did not shift their attributions.

\section{METHOD}

\section{Participants}

Participants were recruited from a single section of introductory psychology. All had scored either a D or an F on the first two exams administered in class. Of the 36 students who met this criterion, 23 participated. Participants were not informed that the study concerned academic performance or that they were chosen due to their low grades. The sample of 23 included 6 male students and 17 female students who participated in small groups ranging from 3 to 5 students. 


\section{Procedure}

Following the first course exam, all students in the class $(N=380)$ completed a questionnaire measuring their attributions regarding performance (Kelley \& Forsyth, 1984). This questionnaire provided a premanipulation measure of the attributions of low-scoring students and served as a check for attributional differences between high- and low-scoring students. Following the second course exam, the students who received Ds and Fs on both tests were contacted and were asked to participate in an experiment (all students were required to gain experience in research settings, through either active participation in an experiment or by performing reading assignments).

Participants were told that they had been chosen, at random, to be included in the experiment. Those who agreed to take part signed up for a single experimental session. Told that the study investigated the "impact of social information on their perceptions," all students gave their informed consent at the beginning of the session. The 12 students who were randomly assigned to the attribution condition were shown a videotape depicting two brief interviews of one male student and one female student discussing their academic performance at the university. Participants were told before the tape began that the interviews were 2 of 50 such interviews conducted in the previous year and that the responses these students gave on the tape were typical of the responses in the other interviews. It was stated that students who were chosen for the interviews had finished their first semester with a low grade point average or GPA ( 2.5 or below) but had improved over the years (high GPA, near 3.5).

In actuality, the interviews were scripted. Both "interviews" began with the students stating that their current GPAs were fairly high (3.4 and 3.7), but their first-semester GPAs were relatively low (2.3 and 2.2). Then the interviewees discussed the causes of their performance. Using different wordings, both students on the tape stated:

1. They had originally blamed their performance on external factors such as task difficulty, bad teachers, roommates, and parents and on uncontrollable factors such as luck and ability.

2. They began, through experience, to attribute their performance to internal, controllable factors such as effort, improving study habits, selfmotivation, and seeking help.

After the videotape, students were presented with a written paragraph and a table of percentages reinforcing statements on the tape about the internal, controllable attributions leading to success in school. This information, supposedly collected by the "Educational Interview Program," reported the results of 50 interviews of students who began school with low grades but who 
eventually achieved high grades. Nearly all these students $(98 \%)$ claimed that they achieved "higher grades once they decided that they caused their own grades, and they had control." In a column format, the report also showed the percentage of successful and failing students who selected various factors as the causes of their academic performance. In all cases, more of the successful students cited the causal impact of internal, controllable factors (effort, internal motivation, self-control, internal control) and more of the failing students cited the impact of external, uncontrollable factors (test difficulty, luck, teachers, quality of high school).

The 11 students who were assigned to the control condition were shown similar interviews, but the content of the message emphasized feelings and attitudes. The students on the videotape were the ones who had appeared on the attribution tape. They said that their grades improved over time, but they did not discuss the causes of their performance. Rather, they discussed their feelings and attitudes toward grades and school in general. In very general terms, they explained that they needed time to "adjust" to school. Control participants were also given a copy of the report made by the Educational Interview Program. This information, however, did not mention the causes of performance. Instead, it focused on feelings and attitudes. Again using a column format, control participants were told that more of the successful students stated they weren't used to college, they liked school and had lots of friends; they were also told that more of the failing students had a negative outlook and questioned the quality of their educational experience. These factors were simply listed; they were not identified as causes of success in college.

\section{Measures}

Manipulation check. After watching the videotape and reading the information sheet, participants completed a questionnaire to assess the effectiveness of the manipulation.

Grades. The primary dependent measures were participants' grades on the third, fourth, and final (cumulative) class exams.

Attributions. Participants' attributions were measured using a questionnaire developed by Kelley and Forsyth (1984). This instrument asks respondents to rate on a 5-point scale the causal impact of 66 factors on the examination performance of the respondents. These 66 causes comprise four global attributional scales, including Inhibiting Factors (bad teacher, unfair test, etc.), Internal Facilitating Factors (high motivation, good study habits, etc.), Uncontrollable Factors (good luck, bad luck, etc.), and External Facilitating Factors (good teacher, good test, etc.). Students completed this 
questionnaire after the first test and once again just prior to the final examination (the questionnaires were mailed to their homes). Scores on each scale could range from 1 to 5 ; the lower the score, the greater the perceived causal significance of the factor.

\section{RESULTS}

\section{Initial Attributions}

To determine if high- and low-scoring students displayed the predicted selfserving attributional biases concerning their performance, their responses on the four scales of the attribution questionnaire were compared in a one-way analysis of variance (ANOVA). As shown in Table 1, the two groups differed dramatically on three of the four global scales. Failing students, relative to successful students, emphasized the causal importance of inhibiting factors and deemphasized the impact of internal and external facilitating causal factors.

\section{Impact of the Manipulation}

The impact of the manipulation on participants was assessed in two ways. First, immediately after exposure to the attributional information, students completed a brief questionnaire assessing their interpretation of the presentation. Second, students' attributions were reassessed just before the final examination to see if the information produced a detectable shift in their attributions.

Perceptions of attributional information. Participants rated both of the students interviewed on the same two questions. One asked "At the time of the interview, the individual in Interview one (two) believed that his/

TABLE 1

High-Scoring and Low-Scoring Students' Attributions: Group Means, $F$ Ratios, and $\rho$ Values

\begin{tabular}{lccccc}
\hline & \multicolumn{2}{c}{ Outcome on Exam } & & \\
\cline { 2 - 3 } Causal Factor & Success & Failure & & \multicolumn{1}{c}{$F$} & $p$ \\
\hline Inhibiting Causes & 4.53 & 3.93 & 66.26 & $<.001$ \\
Internal Facilitating Causes & 1.91 & 2.70 & 65.39 & $<.001$ \\
Uncontrollable Causes & 3.46 & 3.51 & 0.19 & $=.660$ \\
External Facilitating Causes & 2.14 & 2.85 & 58.83 & $<.001$ \\
\hline
\end{tabular}

Note. The higher the mean, the less causal importance assigned to the factor. 
her grades were caused by?" Students responded by checking a point along a 9-point scale ranging from factors that he/she could control (9) to adjustment to school (1). The second question asked "At the time of the interview, the individual in Interview one (two) felt that his/her grades were caused by?" Students responded on a scale ranging from factors inside him/herself (9) to more positive feelings about VCU [Virginia Commonwealth University] (1).

On three of the four items, a one-way ANOVA indicated that the attribution group and control group differed significantly in the predicted direction. Students in the attribution condition reported the interviews focused on internal, controllable causes for grades, whereas the control participants felt the interviewed students discussed feelings toward and adjustment to VCU (see Table 2).

Attributions before the final examination. A one-way ANOVA performed on students' postexperimental attributions revealed a significant effect, $F(1,11)=7.24, p<.05$, for only one global scale - Internal Facilitating Factors. The mean ratings on this scale were 1.89 for the students in the attribution condition and 2.59 for control participants. As predicted, subjects in the attribution condition rated internal facilitating factors as more important causes for grades than did the control participants.

\section{Grade Improvement}

A 2 (Treatment Condition: Attribution vs. Control) $\times 3$ (Test: 3, 4, Final) repeated-measures ANOVA was used to check for improvement between the

TABLE 2

Condition Means, $F$ Ratios, and $p$ Values for Four Items Assessing the Effectiveness of the Experimental Manipulations

\begin{tabular}{llllll}
\hline & \multicolumn{2}{c}{ Condition } & & \\
\cline { 2 - 3 } Item & Attribution & Control & $F$ & $p$ \\
\hline $\begin{array}{l}\text { Person 1 } \\
\text { controllable factors (9) to } \\
\text { adjustment to school (1) }\end{array}$ & 5.42 & 3.91 & 2.59 & $<.12$ \\
$\begin{array}{l}\text { Person 1 } \\
\quad \text { internal factors (9) to } \\
\text { positive feelings (1) }\end{array}$ & 6.58 & 4.00 & 9.25 & $<.01$ \\
$\begin{array}{l}\text { Person 2 } \\
\text { controllable factors (9) to } \\
\text { adjustment to school (1) }\end{array}$ & 6.33 & 3.55 & 6.53 & $<.05$ \\
$\begin{array}{l}\text { Person 2 } \\
\text { internal factors }(9) \text { to } \\
\text { positive feelings (1) }\end{array}$ & 7.00 & 4.36 & 10.68 & $<.01$ \\
\hline
\end{tabular}


attribution and the control conditions over the three exams. Main effects for condition, $F(1,24)=3.52, p<.05$, and for test, $F(2,24)=3.40, p<.01$, reached significance. The test score means (Table 3) indicate that students who received information that stressed the impact of internal, controllable factors on performance scored higher than control participants on all three exams. Students assigned to the attribution condition answered, on average, $75 \%$ of the questions correctly (letter grade of $\mathrm{C}$ ), whereas those in the control condition had an average of $62 \%$ correct (letter grade of D). This improvement also increased gradually over time. The interaction between condition and test was not significant.

\section{DISCUSSION}

When low-scoring students were prompted to change their attributions about the cause of their educational outcomes, their performance improved. As expected, students who performed poorly on their initial course examination displayed a pattern of self-serving attributions: They blamed their failure on external, inhibiting factors such as the teacher, the ambiguity of the textbook, or the unfairness of items on the test. The high-scoring students, in contrast, emphasized the impact of both internal and external facilitating factors such as effort and study habits. However, when this self-defeating pattern of causal attributions was interrupted, the failing students' grades improved relative to those of participants in a control condition. The participants who received internal, controllable attributional information scored higher on the third, fourth, and final examinations than those in the control - no attributional information - condition. The average grade for attribution participants was $\mathrm{C}$, whereas the average grade for control participants was D.

The marked improvement in performance of the participants exposed to internal, controllable information is encouraging, but a number of limita-

TABLE 3

Average Test Scores (Percentages Correct)

of Students in the Experimental and Control Conditions

\begin{tabular}{lcc}
\hline & \multicolumn{2}{c}{ Condition } \\
\cline { 2 - 3 } Test & Attribution & Control \\
\hline 3 & 76 & 64 \\
4 & 65 & 57 \\
Final & 83 & 64 \\
Average & 75 & 62 \\
\hline
\end{tabular}


tions should be noted. First, we only examined a relatively small number of low-scoring students. Second, due to the small number of male students in the study, we could not test for any differences between the men and women who participated. Third, the impact of the intervention on students cannot be identified precisely. The manipulation checks used immediately after the sessions focused on students' awareness of the content of the interviews they watched, but they did not assess change in students' attributions about their own performance.

These limitations, however, are offset by the fact that significant differences were obtained (despite the relatively small number of low-scoring students) and by the limited evidence of attributional change in students who improved their grades throughout the semester. Previous studies have often found that attributional interventions lead to changes in performance, but in many cases self-report measures fail to detect any appreciable change in attributions. The training procedures used in this study, however, produced measurable changes in attributions at the time of final measurement. Further research is needed, however, to determine the temporal order in this sequence of events: Did the students first change their attributions, and then improve their grades, or did the improvement in their grades prompt them to change their attributions?

A final limitation of the study stems from the decision not to include a "pure" control condition in which participants received no treatment whatsoever. The control condition in the current study was, in many respects, a conceptual replication of the intervention used by Wilson and Linville (1982) in their research. Based on their results, we expected that both treatments used in the current investigation would be effective but than an explicit focus on internal/controllable causes would yield increments beyond those obtained by Wilson and Linville. Yet, without a no-treatment condition, we cannot tell if the "baseline" intervention used in this study increased grades slightly (thus replicating Wilson and Linville) or if this treatment actually interfered with performance. The information presented to control participants in this study stressed the way grades improve gradually over time but did not point out the causal factors that mediate this change. If the participants in this condition concluded that grades improve independently of their efforts, they may have concluded that they could do little to control their outcomes. This conclusion could have led to a loss of achievement motivation.

This interpretation of the results cannot be dismissed, but a limited amount of evidence argues against it. First, the control participants were no more likely than the students in the attribution condition to attribute their outcomes to external, uncontrollable factors. The two conditions differed attributionally in only one way: Relative to the control participants, students in the attribution condition attributed their outcome more to internal, facilitating causes. Also, the value of both attributional interventions can be 
assessed by examining the reactions of low-scoring students who were asked to participate in the experiment but did not volunteer. These individuals tended to drop out of the class. Six of the 13 students $(46 \%)$ who did not take part in the study stopped attending, whereas all who participated in the group sessions remained in the course until the end of the semester, regardless of condition.

These findings yield a number of theoretical, methodological, and practical implications. At a theoretical level, students' reactions are consistent with Weiner's model of achievement motivation. Although Weiner originally suggested that two dimensions-internality and stability-account for variations in students' attributions, he recently amended the model to include a controllability dimension (Weiner, 1979). Supporting his reformulated model, the current findings demonstrate that attributions and performance are linked. The students who participated in this experiment began the study with defensive, self-serving attributions that emphasized external, uncontrollable causes. When their attributions were shifted experimentally to emphasize internal, controllable attributions, their relative performance improved. Although the mediators of this improvement in performance are not yet known, the current findings suggest that attributions can cause changes in performance.

Methodologically, the findings also suggest that attributions can be manipulated directly. Relative to control participants, students who were exposed to (a) vivid case data (two students discussing the causes of their performance) and (b) statistical data that bolstered the information contained in the cases attributed their performance to internal, facilitating causes such as high motivation. These findings, when combined with the results of prior studies of attributions that involved relatively direct attempts to manipulate attributions (e.g., Dweck, 1975; Forsyth \& Forsyth, 1982; Wilson \& Linville, $1982,1985)$, suggest that individuals, in their search to identify causal forces, rely on objective as well as subjective sources of causal information.

Lastly, on the practical side, if attributions influence educational outcomes (Forsyth, 1986; McMillan \& Forsyth, 1981), these findings suggest that educators should help their students arrive at the most adaptive, educationally beneficial causal conclusions possible. For example, the bulk of the evidence indicates that the student's first attributional inclination after failure-externalization-does not facilitate learning, help seeking, or increased persistence. To counteract these "natural" tendencies, educators should encourage students to explore the causes of their success and failure and guide them toward achievement-promoting conclusions about causality. If students who do poorly in class conclude there is nothing they personally can do to change their outcomes, then their failure could undermine their motivation and satisfaction with self and with schoolwork. However, if the 
teacher encourages students to associate failure with factors that can be controlled, then the debilitating consequences of failure may be avoided.

\section{ACKNOWLEDGMENTS}

This article is based on an honors thesis submitted by the first author to the Department of Psychology at Virginia Commonwealth University. Thanks are extended to committee members Joseph Bush, Barbara Myers, and Joseph Porter for their help and encouragement and to Patty Baker and Edwin Tisdale for acting in the stimulus videotapes.

\section{REFERENCES}

Ames, R., \& Lau, S. (1982). An attributional analysis of student help-seeking in academic settings. Journal of Educational Psychology, 74, 414-423.

Arkin, R. M., Kolditz, T. A., \& Kolditz, K. K. (1983). Attributions of the test-anxious student: Self-assessments in the classroom. Personality and Social Psychology Bulletin, 9, 271-280.

Arkin, R. M., \& Maruyama, G. M. (1979). Attribution, affect, and college exam performance. Journal of Educational Psychology, 71, 85-93.

Bernstein, W. M., Stephan, W. G., \& Davis, M. H. (1979). Explaining attributions for achievement: A path analytic approach. Journal of Personality and Social Psychology, 37, $1810-1821$.

Block, J., \& Lanning, K. (1984). Attribution therapy requestioned: A secondary analysis of the Wilson-Linville study. Journal of Personality and Social Psychology, 46, 705-708.

Covington, M. V., \& Beery, R. (1976). Self-worth and school learning. New York: Holt, Rinehart \& Winston.

Covington, M. V., \& Omelich, C. L. (1979). Are causal attributions causal? A path analysis of the cognitive model of achievement motivation. Journal of Personality and Social Psychology, 37, 1487-1504.

Covington, M. V., \& Omelich, C. L. (1981). As failures mount: Affective and cognitive consequences of ability demotion in the classroom. Journal of Educational Psychology, 73, 796-808.

Dweck, C. S. (1975). The role of expectations and attributions in the alleviation of learned helplessness. Journal of Personality and Social Psychology, 31, 674-685.

Forsyth, D. R. (1980). The functions of attributions. Social Psychology Quarterly, 43, 184-189.

Forsyth, D. R. (1986). An attributional analysis of students' reactions to success and failure. In R. S. Feldman (Ed.), The social psychology of education (pp. 17-38). New York: Cambridge University Press.

Forsyth, D. R., \& McMillan, J. H. (1981). Attributions, affect, and expectations: A test of Weiner's three dimensional model. Journal of Educational Psychology, 73, 393-401.

Forsyth, D. R., \& Schlenker, B. R. (1977). Attributing the causes of group performance: Effects of performance quality, task importance, and future testing. Journal of Personality, 45, 220-236.

Forsyth, N. L., \& Forsyth, D. R. (1982). Internality, controllability, and the effectiveness of attributional interpretations in counseling. Journal of Counseling Psychology, 29, 140-150. 
Greenwald, A. G. (1980). The totalitarian ego: Fabrication and revision of personal history. American Psychologist, 35, 603-618.

Kelley, K., \& Forsyth, D. R. (1984, April). Attribution-affect linkages after success and failure. Paper presented at the annual meeting of the Eastern Psychological Association, Baltimore.

Kovenklioglu, G., \& Greenhaus, J. H. (1978). Causal attributions, expectations, and task performance. Journal of Applied Psychology, 63, 698-705.

McMillan, J. H., \& Forsyth, D. R. (1981). The impact of social psychological factors on school learning: An overview. Representative Research in Social Psychology, 12, 20-31.

Miller, R. L., Brickman, P., \& Bolen, D. (1975), Attribution versus persuasion as a means for modifying behavior. Journal of Personality and Social Psychology, 31, 430-441.

Schunk, D. H. (1983). Ability versus effort attributional feedback: Differential effects on selfefficacy and achievement. Journal of Educational Psychology, 75, 848-856.

Snyder, M. L., Stephan, W. G., \& Rosenfield, D. (1978). Attributional egotism. In J. Harvey, W. Ickes, \& R. Kidd (Eds.), New directions in attribution research (Vol. 2, pp. 91-117). Hillsdale, NJ: Lawrence Erlbaum Associates, Inc.

Weiner, B. (1979). A theory of motivation for some classroom experiences. Journal of Educational Psychology, 71, 3-25.

Wilson, T. D., \& Linville, P. W. (1982). Improving the academic performance of college freshmen: Attribution therapy revisited. Journal of Personality and Social Psychology, 42, 367-376.

Wilson, T. D., \& Linville, P. W. (1985). Improving the performance of college freshman with attributional techniques. Journal of Personality and Social Psychology, 49, 287-293.

Zuckerman, M. (1979). Attribution of success and failure revisited, or: The motivational bias is alive and well in attribution theory. Journal of Personality, 47, 245-287. 